\title{
System or Process? A Meta-theoretical Reflection on the Nature of the Firm
}

\author{
Vladislav Valentinov ${ }^{1}$ (D)
}

Accepted: 1 January 2021 / Published online: 29 January 2021

(c) The Author(s) 2021

\begin{abstract}
The paper revisits the fundamental question of the nature of the firm by contrasting two philosophic worldviews suggested by process philosophy and the Luhmannian systems theory. Whereas the former worldview takes reality to be internally related, the latter ones underscores the tendency of social systems, such as firms, to disregard much of this interrelatedness. The productive tension between these worldviews suggests that the firm provides a context where systemic imperatives meet the rich concrete reality of human life. The role of the firm is to house those aspects of this reality that are too organic to be accommodated by the abstract "language of prices" corresponding, in institutional economics terms, to the reliance on market governance. The major examples of these aspects explored in the paper are dynamic capabilities and business ethics, both of which hold the potential to improve the firm's sustainability, both economic and social. The proposed contrast between the process-philosophic and systems-theoretic worldviews thus illuminates not only the nature of the firm but also the managerial relevance of corporate sustainability instruments.
\end{abstract}

Keywords Business ethics $\cdot$ Process philosophy $\cdot$ Systems theory $\cdot$ Theory of the firm

\section{Introduction}

Since its explicit formulation by Ronald Coase (1937), the problem of the nature of the firm has provided impetus for extensive scholarship spanning many disciplines, such as economics, management, organization theory, sociology, political science, and business ethics. Much of this scholarship provides a fertile ground for the emergence of metatheoretical and philosophical perspectives, the premier varieties of which are social systems theory and process studies. In view of the pervasive and dramatic nature of challenges faced by corporations in the globalized world, such perspectives are gaining increasing traction, particularly in the fields of management and organization science (cf. Jackson 2019). The present paper contributes to the philosophic inquiry into the nature of the firm by probing the complementary implications of assuming the nature

Vladislav Valentinov

valentinov@iamo.de

1 Leibniz Institute of Agricultural Development in Transition Economies, Theodor-Lieser-Str. 2,

06120 Halle, Germany 
of the firm to reside in the systems-theoretical function of complexity as theorized by Luhmann and alternatively conceptualizing the firm in process-relational terms as "an attempt at stabilization in a changing world" (Hernes 2008, p. 57), or "a tangled relationship of human and physical factors which shape each other in constant interaction" (ibid, p. 34). The complementarity of main concern to the present paper is, therefore, rooted in the apparent ability of process thinking to disentangle the apparent paradox contained in the conceptualization of the firm as a complexity-reducing social system.

The Luhmannian systems-theoretic approach points to the highly fragile and precarious nature of the relations of many business firms to their societal and natural environment. Luhmann argued that operational closure as the attribute of social systems is associated with the selective indifference of such systems to major chunks of their inner and outer environment (e.g., Luhmann 1995, p. 183). Yet, the degrees of freedom enjoyed by social systems in virtue of their operational closure carry "the risk that systems develop insensitivity to those environmental conditions on which they critically depend" (Valentinov 2014, p. 14). In the latter case, social systems suffer from sustainability problems, which, paradoxically, often do not result in the immediate elimination of the unsustainable systems. It is in dealing with this paradox that a Luhmannian systems-theoretic approach can draw useful insights from process thinking. In a book devoted to the ecological crisis of the modern society, Luhmann (1989, p. 14) admitted that "the primary goal of autopoietic systems is the continuation of autopoiesis without any concern for the environment... Viewed from a long term perspective, evolution is concerned about reaching 'ecological balances'. But this merely means that systems pursuing a trend toward exposure to ecological self-endangerment are eliminated". Indeed, the very fact that a broad range of sustainability problems persist for a long time indicates that many unsustainable systems could avoid being eliminated, at least up to now. At the same time, the paradigmatic focus of the Luhmannian systems theory on complexity reduction, and hence on the selective disregard of the environmental complexity, may be partly responsible for the perception that this theory gives an incomplete account of the mechanisms of environmental anchoring of social systems (Roth and Valentinov 2020).

The perceived blind spot in the systems-theoretic analysis of sustainability problems may be conveniently illustrated on the example of what Valentinov (2014) calls "the complexity-sustainability trade-off" that he discerns in the Luhmannian systems theory. Valentinov derives the trade-off by juxtaposing two principles that seem to be implicit in his reconstruction of the Luhmannian vision of system-environment relations. According to the complexity reduction principle, "systems increase their complexity by becoming increasingly insensitive to the complexity of the environment" (ibid, p. 18). According to the critical dependence principle, "the increasing complexity of systems is associated with their growing dependence on environmental complexity" (ibid). Whereas the complexity reduction principle can be said to be one mainstay of Luhmann's work, the notion of critical dependence of systems on their outer environment seems to present rather an antithesis to complexity reduction and does not become fully clear within the Luhmannian paradigm; and whereas this trade-off between complexity and sustainability is far from being inevitable, it corresponds well with the widespread idea that the greater the complexity of a system, the greater the sustainability risks associated with it. It is probably for this reason that Valentinov resorted to linking the critical dependence principle with the open systems theory of Ludwig von Bertalanffy (1968), while his understanding of the complexity reduction principle remains 
clearly grounded on the notion of operational closure as a centrepiece of autopoietic systems theory.

The main contention of the present paper is that the historical gravity of the critical dependence principle can be usefully illuminated by process thinking which "invites us to think about individuals, organizations and social entities in terms of ceaseless change, emergence and self-transformation" (Nayak and Chia 2011, p. 282). Change and self-transformation are indeed endemic to the representations of steady-state and metabolism in the open systems theory. No less crucially, process thinking, especially at the hands of Alfred North Whitehead, embraces the idea of internal relations, which means that "everything that is arises out of multiple other things and has no existence apart from their relations to them. This is best understood if we think of the world as made up of happenings, occurrences, or events. Each event arises out of other events and is nothing apart from their participation in its constitution" (Cobb 2007, p. 568). Accordingly, critical dependence in the framework of the complexity-sustainability trade-off can be conceptualized as the Whiteheadian relation of a system's "internal relations" to their outer environment. Yet, according to Whitehead, the rich complexity of this relation defies the limits of abstract thinking practiced by persons, p. "The advantage of confining attention to a definite group of abstractions, is that you confine your thoughts to clear-cut definite things, with clearcut definite relations... The disadvantage of exclusive attention to a group of abstractions, however well-founded, is that, by the nature of the case, you have abstracted from the remainder of things" (Whitehead 1929, pp. 72 et seq.).

In terms of the complexity-sustainability trade-off, Whitehead's acknowledgment of the advantage of abstract thought is tantamount to recognizing the useful function of complexity reduction. Just as the systemic complexity reduction function seems to abstract from the critical dependence of social systems on their environment, Whitehead $(1978$, p. 7$)$ referred to the "fallacy of misplaced concreteness" which "consists in neglecting the degree of abstraction involved when an actual entity is considered merely so far as it exemplifies certain categories of thought. There are aspects of actualities which are simply ignored so long as we restrict thought to these categories". In other words, the fallacy highlights "the error of mistaking the abstract for the concrete" (Whitehead 1929, p. 64). One might conjecture that the implications of this fallacy for the nature of system-environment relations can be well described in terms of "a lack of reverence in the treatment of natural or artistic beauty" (ibid, p. 243). Whitehead refers in this context to "two evils": "one, the ignoration of the true relation of each organism to its environment; and the other, the habit of ignoring the intrinsic worth of the environment which must be allowed its weight in any consideration of final ends" (ibid, p. 244). These "evils" translate directly into the tendency of social systems to underestimate the importance and complexity of their critical environmental dependencies, and thus to suffer from sustainability problems. This point is well acknowledged by Mesle (2008, p. 11): "unless we can take seriously the ecological, cultural, religious, and economic interwovenness of our lives in this world, we are in serious danger of self-destruction. Process philosophy can help us come to that vital self-understanding".

This paper will explore the implications of this process-philosophic insight for the context of the theory of the firm. Following Luhmann, systems-theoretical scholars have consistently (over-) defined the firm as a complexity-reducing system. The growing scholarly interest in understanding the processual nature of the firm (cf. Langley and Tsoukas 2017) suggests that, by virtue of the very nature of complexity reduction, this description cannot be complete. In discussing the reductionist nature of abstractions produced by the classical political economy, Whitehead (1929, p. 249) stressed that "a factory, with its machinery, its community of operatives, its social service to the general population, its dependence upon 
organising and designing genius, its potentialities as a source of wealth to the holders of its stock is an organism exhibiting a variety of vivid values. What we want to train is the habit of apprehending such an organism in its completeness". The contribution of process thinking, especially of Whitehead's own making, is to expose the nature and significance of this completeness, against the background of the crucial systems-theoretic insight into the firm's complexity-reducing function. The paper will revisit some of the recent Luhmannian systems-theoretic accounts of the nature of the firm and lay bare the ways in which the critical dependencies of the firm on its outer societal environment reveal the firm as a Whiteheadian "organism" embedded in the evolving web of relations with the rest of a modern world that "provides one world for one system; and it integrates all world horizons as horizons of one communicative system" (Luhmann 1982, p. 133). While the systemstheoretical emphasis on the complexity-reducing function is certainly not inadequate, the realization of its true potential requires a better appreciation of the firm as a web of internal relations. The subsequent sections contribute to this appreciation by revisiting the nature of system-environment relations in the context of the theory of the firm, the origins of the dynamic capabilities of the firm, and the understanding of business ethics.

\section{Systems Theory and the Theory of the Firm}

In spite of the wide spectrum of the Luhmannian scholarship on the nature of formal organizations and managerial practice (Ahrne et al. 2016; Cooren and Seidl 2019; GrotheHammer 2019; Hernes and Bakken 2003), the Luhmannian themes in the economic theory of the firm have received a relatively scant attention (Roth et al. 2020; Plaza-Úbeda et al. 2020; Valentinov and Thompson 2019; Thompson and Valentinov 2017; Valentinov 2020). Thompson and Valentinov's (2017) systems-theoretic assessment of the mainstream contract-based and competence-based theories of the firm has led them to conclude that these theories are paradigmatically based on the firm's complexity-reducing function. According to the authors, "the determining factors in both contract-based theories (namely asymmetric information) and competence-based theories (namely tacit/collective knowledge, uncertainty, and bounded rationality) either stem from, or are made salient by, environmental complexity" (ibid, p. 1069). At root, these theories explore the ways in which the firm as a social system brings environmental complexity down to the level of limited cognitive capacities of individual human agents. To the extent that this complexity reduction is successful, firms achieve cooperation (stressed by the contract-based theories) and coordination (stressed by the competence-based theories) in such a way as "to coordinate complex processes of production and exchange that are beyond the knowledge, information and intelligence of any single participant (Valentinov and Thompson 2019, p. 574).

Thompson and Valentinov (2017, p. 1061) doubt, however, that the two types of the theories of the firm are fully successful, for they "acknowledge the importance of trust and loyalty but neglect such behaviour in the substance of their analyses". This neglect is a specific manifestation of the perceived complexity-sustainability trade-off which means, in the present context, that the paradigmatic focus of the economic theory of the firm on complexity reduction has an opportunity cost in the form of the lacking appreciation of the multifarious dependencies of the firm on its societal and ecological environment (cf. Keahey 2020). Thus, from the systems theory perspective, firms "can be expediently conceptualised as social systems, whose complexity-reducing function leads them to disregard their critical environmental dependencies and thus undermine their own sustainability" (ibid, p. 
1078). In their more recent work, the authors draw "inspiration from the classic Marshallian presentation of supply and demand in modern economics [to argue] that the principles of complexity reduction and critical dependence translate into the demand for and supply of social systems" (Valentinov and Thompson 2019, p. 570). This analogy makes clear that any theory of the firm cannot be balanced if it pays more attention to demand than supply.

Yet, given the perceived paradigmatic bias of the Luhmannian systems theory to complexity reduction, the guidance that this theory may be expected to be of only little use for constructing the balanced explanations of the firm. This is where the Whiteheadian doctrine of internal relations comes into play. At first sight, this doctrine poses a certain challenge to the conceptualization of operational closure of the firm as a social system. A plausible interpretation of operational closure is that a personal affiliation with the firm occurs in the framework of the narrowly defined roles which are not at all supposed to account for the full context of real-life situations in which specific firm stakeholders (such as employees) may find themselves. At the same time, a plausible interpretation of the doctrine of internal relations is that the firm thrives, if it does, on the full utilization of personal capacities which are shaped and maintained within the web of rich social interactions, and which go far beyond the narrow contexts of specific formal organizations. In other words, the firm as a social system might be, in principle, able to "instrumentalize" the rich web of environmental relations in a similar fashion that the living organism "instrumentalizes" diverse environmental resources to maintain its own existence. Furthermore, this "instrumentalization" does not need to be seen as contrary to the operational closure of the firm.

The suggested interpretation of operational closure and internal relations seems to draw support from Chester Barnard's (1938) classic theory of formal organization. Barnard shared the Luhmannian penchant for the study of system-environment relations and had a deep understanding of the formal organization's operational closure, even if he did not use the term. In his theory, operational closure is clearly implied in the distinction between two aspects in the relation of employees to their organizations: "in the first aspect, some of the activities of the person are merely a part of a non-personal system of activities; in the second aspect the individual is outside, isolated from, or opposed to the cooperative system" (Barnard 1938, p. 17). This distinction retains some validity despite the fact that, according to Barnard, the individual decides about participating in the organization in the light of its whole life context which is clearly outside of the organization. Accordingly, Barnard's theory of organizational equilibrium holds that organizational survival depends on loyalty, solidarity, sense of purpose, and "sustained personal effort as a contribution to cooperation" (ibid, p. 84), even though all these conditions evidently involve the employee's whole personality in the rich web of social interactions. Furthermore, according to Wolf (1974, p. 87), Barnard believed the extent of responsibility in formal organizations to frequently exceed the extent of authority, in such a way that the emerging gap between them can be only compensated by personal loyalty and commitment which are inseparable from the context of the employee's whole personality.

Even a hard-core contract-based theory of the firm, such as that by Alchian and Demsetz (1972), can be shown to assume this commitment. Alchian and Demsetz explain the rationale of the firm in terms of the need to control shirking behaviour in the setting of team production "wherein individual cooperating inputs do not yield identifiable, separate products which can be summed to measure the total output. For this cooperative productive activity, here called 'team' production, measuring marginal productivity and making payments in accord therewith is more expensive by an order of magnitude than for separable production functions" (ibid, p. 779). The main reason for this expensiveness is that the shirking behaviours of individual cooperating inputs cannot be directly observed 
and sanctioned. Accordingly, the "centralized contractual agent", whose existence Alchian and Demsetz (ibid) assume to be defining characteristic of the firm, must rely on indirect observational clues: "when lifting cargo into the truck, how rapidly does a man move to the next piece to be loaded, how many cigarette breaks does he take, does the item being lifted tilt downward toward his side?" (ibid, p. 780). The suggested examples of the clues are highly significant. The subtle humour contained therein indicates that the centralized contractual agent must develop a high degree of personal creativity in order to be maximally responsive to a real-life situation whose formal and informal dimensions are hard to disentangle. This creativity requires commitment whose practical meaning goes beyond anything that can be specified in a formal contractual relationship. A similar requirement of creativity and commitment is likewise assumed by the competence-based theories. In terms of Barnard's organization theory, this requirement fills the gap by which the extent of individual authority in the formal organization falls short of the extent of responsibility (cf. Wolf 1974, p. 87).

\section{A Processual View of Dynamic Capabilities of the Firm}

The harnessing of the full context of local real-life situations seems to have relevance to a key issue of the competence-based theories of the firm and the nature of dynamic capabilities as discussed in the recent work by Nayak et al. (2019) and Chia (2017). According to Barney's (1991) seminal rendition of the resource-based view of the firm, dynamic capabilities can generate a sustainable competitive advantage of the firm if they are valuable, rare, inimitable, and non-substitutable. As Nayak et al. (2019) aptly discern, the extensive scholarship on dynamic capabilities ultimately fails to provide a satisfactory account of the origins of the inimitability and hence idiosyncrasy of dynamic capabilities. Equally mysterious remain their tacit and opaque character. Given these features, Nayak et al. (2019) wonder about the extent to which the evolution of dynamic capabilities across firms in specific markets and industries might converge around coherent patterns. To address this issue, the authors advance the ecological approach buttressed by a new vocabulary of processinspired terms, such as environmental affordances, empirical sensitivities, and habitus, the latter of which clearly goes back to the work of Bourdieu.

A possible reading of the contributions by Nayak et al. (2019) and Chia (2017) suggests that the processes of organizational learning can be analysed along two dimensions corresponding to the complexity reduction and critical dependence principles of the complexity-sustainability trade-off. If organizational learning is informed by complexity reduction, it deemphasizes contextual embeddedness and boils down to deliberate information processing and accumulation with a view to overcoming the limits of the individual cognitive capacities. Dynamic capabilities and routines arising out of this type of organizational learning can be thought of as "best practices" (Eisenhardt and Martin 2000) that may potentially become common across specific firm populations, for the complexity-reducing function is indeed generic for all types of social systems. If organizational learning occurs along the lines of the critical dependence principle, it acquires different features which may account for idiosyncrasy, inimitability, and opacity of dynamic capabilities. Informed by the latter principle, organizational learning seeks to embrace, rather than reduce, environmental complexity. Whereas Luhmann explicitly associated complexity reduction and operational closure of social systems, such as firms, with the selective indifference toward the environment, the critical 
dependence principle underscores the requirement of systemic sensitivity to the environment, at least as long as the environment remains capable of tolerating the system in question. Following Chia's (2017) terminology, the types of organizational learning governed by the critical dependence and complexity reduction principles can be respectively titled as cognitive and non-cognitive. His work can be taken to suggest that the former type of learning can take place only after the latter type has place. "Social practices" underpin the "prior unconscious adaptive and improvisatory learning" (ibid, p. 108) and thus provide the substrate for the cognitive learning informed by the complexity reduction principle.

Thus, the distinctive feature of the noncognitive learning associated with the critical dependence principle is contextuality and "immersive engagement with the world" (Nayak et al. 2019) which includes the rich web of social interactions whose formal and informal dimensions are hardly separable. If so, then the Luhmannian framework and the complexity-sustainability trade-off may indeed explain how each firm can be idiosyncratic. A basic postulate of the Luhmannian theory is that the environment exhibits overwhelming complexity for which no social system can mobilize sufficient "requisite variety". For Luhmann, a system is, therefore, embedded in its environment via the idiosyncratic structural couplings to this environment. Yet, from the process perspective, the overwhelming environmental complexity translates into the overwhelming diversity of idiosyncratic contexts in which all social systems, including firms, are embedded. Operating according to the complexity reduction principle, firms may indeed disregard many of these contexts; but the noncognitive learning strategies corresponding to the critical dependence principle lead the firms to refine their "empirical sensitivities" in such a way as to recognize and take advantage of their "environmental affordances" (Nayak et al. 2019). Obviously, these affordances are contextual and unique, and cannot be recognized by disregarding the environment. Teece (2012, p. 1396) suggested to understand dynamic capabilities in terms of the firm's ability to "sense", "seize", and "transform" environmental opportunities. An implication of his approach is that the development of dynamic capabilities goes against the grain of complexity reduction.

This stark conclusion notwithstanding, it is evidently true that firms equally require both cognitive and non-cognitive learning strategies, which accordingly sustain a relationship of mutual complementarity. The former strategies may be supposed to be triggered when the familiar routines and habits are disrupted or bring unexpected outcomes. This may be the case when "objects and relations are conspicuous (they no longer work in the normal way), when they obtrude (they become absent) or when they obstruct (they are experienced as obstacles)" (Chia and Holt 2006, p. 649). The non-cognitive learning strategies may thus be supposed to be subject to "complexity limits" that may be overcome if firms are able to resort to the cognitive strategies. In contrast, in line with the complexity-sustainability trade-off, the latter strategies may be supposed to be subject to the "sustainability limits", as the orientation toward complexity reduction may bring firms to disregard their critical environmental dependencies. Whereas Valentinov (2014) associated these limits primarily with social and ecological sustainability, Nayak et al.'s (2019) work on dynamic capabilities suggests that these limits may likewise pertain to the economic dimension, and more specifically to the firm's competitive advantage, which may or may not be sustainable. Whether ecological, social, or economic, the required sustainability calls for an enhanced systemic sensitivity to the environment. Given that this sensitivity is framed by the critical dependence at least as much as by complexity reduction principles, its nature cannot be fully grasped by 
cognitive strategies. It is for this reason that dynamic capabilities related to this sensitivity are characterized as inimitable, tacit, and opaque (cf. Teece 2007, p. 1321).

\section{A Processual View of Business Ethics}

If the refined sensitivity to environment underpins the firm's sustainable competitive advantage, it is even more crucial for securing the firm's ability to respond to societal expectations and to uphold thereby their "license to operate". The importance of the latter ability is widely established in the extensive literatures on business ethics and corporate social responsibility. In the 1953 classic, Howard Bowen maintained that "it is becoming increasingly obvious that a freedom of choice and delegation of power such as businessmen exercise would hardly be permitted to continue without assumption of social responsibility" (Bowen 1953, p. 6). He saw the nature of this responsibility in "the obligations of businessmen to pursue those policies, to make those decisions or to follow those lines of action which are desirable in terms of the objective and values of our society" (ibid, p. 6). In line with the modern emphasis on the business case for corporate social responsibility, he did not believe in the antagonistic opposition between the interests of corporations and their societal stakeholders. He discerned that corporate managers are increasingly seeing the contribution to societal welfare, rather than profit maximization, to be the touchstone of business success (ibid, p. 52). If "the welfare of society is related not only to the quantity of final goods and services, but also to the conditions under which these goods and services are produced" (ibid, p. 113), then the corporate social responsibility for improving these conditions will ultimately correspond to the direct economic interest of corporations (cf. Pies et al. 2019; Ramírez et al. 2019).

While Bowen believed in the possibility of convergence of economic interests and social responsibilities in the framework of what he called institutionalization processes, he was far from denying the economic logic of profit maximization faced by corporate managers. In that sense, he may be said to have upheld the operational closure of the economic system. Against the backdrop of operational closure, it is noteworthy that he considered corporate managers to be capable of registering the evolving societal demands, particularly due managers' socialization in the respective societal environment. As he put it, "the businessman has been subjected to pressure originating from the new social climate in which he operates, and at the same time he himself has assimilated many of the values and attitudes that are characteristic of this new social climate" (Bowen 1953, p. 75; cf. Wabule 2020). Acquier et al. (2011, p. 636) affirm that "for Bowen, the businessman is not a lone, calculating actor. His behaviour is embedded within social and organizational contexts". Thus, Bowen not only considered managers to be persons with a unique history and social awareness, he must also have assumed that corporations have dynamic capabilities of sorts to sense societal expectations before they become fully institutionalized, if the institutionalization processes are to get off the ground. These dynamic capabilities are evidently functionally similar to those theorized by the resource-based view of the firm. Just like the latter ones, they allow the firm to refine its sensitivity to its critical environmental dependencies but pertain primarily to the dependencies on the societal rather than economic environmental segments (Valentinov and Perez Valls 2021).

Sensitivity to environment, however, is not only a precondition of positive relationships between corporations and their societal stakeholders. This sensitivity is likewise implicated in the emergence of "business ethics as practice" (Painter-Morland 2008) lived by 
corporate employees (cf. Tortia 2018). Understood as "practice", business ethics in corporations radically differs from "many corporate ethics programs [which] have become no more than 'insurance policies' against corporate liability and are implemented and managed with an indiscriminate 'checkbox' mentality" (ibid, p. 1). Instead, Painter-Morland (ibid, p. 3) proposes to understand business ethics as "the capacity to respond appropriately to the many competing pressures and expectations that push and pull individuals in the course of their daily participation in complex organizational and business networks. It requires an intuitive and continuous balancing act, in which an individual's character, values, and relationships all register in significant ways". Business ethics as practice evidently means full responsiveness of employees to their dense webs of personal relationships which go far beyond the limits of the operational closure of both the economic system and thus also beyond the limits of the social responsibility and similar forms of "aspirational talk" (Christensen et al. 2013) of the formal organization with which the employees are affiliated. An implication of this argument is that the practical meaning of business ethics in corporations can be analysed through the lens of the complexity reduction and critical dependence principles. The complexity reduction principle would, at least on face value, be consistent with the institutionalized and bureaucratized management of ethics programs and codes, whereas the critical dependence principle would stress context, relationality, and the genuine furthering of social life.

The latter goal is assumed to be particularly attainable through values, which, in the business context, are said to "have the unique ability to solicit the voluntary support of individual employees. They emerge as a kind of inarticulate pattern or quality in the behaviour and expectations of those who participate in an organizational system. They create a certain congruence, both in the actions of an individual over time and under different circumstances, and in the behaviour of all those who identify with a particular organization. ... Through their emergence, an organization's employees develop a sense of propriety that guides decision making more effectively than the deliberate application of principled thought" (Painter-Morland 2008, p. 174) framed by the complexity reduction principle. The "sense of propriety" noted by Painter-Morland (ibid) evidently denotes the sensitivity of employees to the corporate societal environment constituted by the rich webs of personal relationships inextricably harnessed in the corporate efforts to withstand the moral challenges and seductions of globalized capitalism. If this interpretation is correct, business ethics as practice may indeed be the most important dynamic capability essential not only for the competitive advantage but also for the very survival of corporations in the midst of the turbulent social life.

\section{Toward a Processual Perspective on the Nature of the Firm}

In a highly discerning argument, Tor Hernes (2008, p. 94) identified several overarching differences in the thought of Luhmann and Whitehead. Contrary to Luhmann, "boundary drawing does not occupy a major role in Whitehead's work... Luhmann's reasoning, on the other hand, dictates that without boundary drawing there is no difference between one system and another" (ibid). Furthermore, whereas Luhmann emphasized "inward connecting processes of systems", Whitehead put stress the on the outward connections (ibid). Arguably, the Whitehead-Luhmann contrast contain rich implications for systems theory and process studies, as well as the theory of the firm. In terms of systems theory, these contrasts illuminate the relationship between the complexity reduction and critical dependence 
principles along the lines drawn by the structural couplings of system and environment. In terms of process studies, these contrasts correspond with Hernes's (2008, p. 54) suggestion that concrete experience and abstraction are complementary and infuse each other with meaning. In the context of the theory of the firm, the Whitehead-Luhmann contrast suggests a new as processual as systemic perspective on the question about the nature of the firm. The firm may be understood as a platform where personal (or even spiritual) and organizational observations cross-fertilize each other and thereby create a new contrast which serves, in terms of Whiteheadian ethics, to enhance the depth and intensity of either form of observation. The firm is a platform where organizational imperatives meet thick personal descriptions and worldviews. In the course of this meeting, personal life can be enhanced (or debased), and organizational imperatives propel interaction (which may be more or less productive or opportunistic).

While the possible range of processual approaches to the nature of the firm is hardly exhaustible, the advantage of the perspective proposed above is that it throws sidelights on the fundamental question of the specification of the boundary between the firm and the market (Foss 1993; Hodgson 1998; Kroszner and Putterman 2009; Zenger et al. 2011). In radicalising Luhmann, Roth (2018, p.132f) interprets the market not only as the inner environment of the economic function system, but rather as the intra-societal horizon of all forms of organized communication. Accordingly, this multifunctional market may be segmented into and features mutual influences between, inter alia, economic, political, scientific, legal, religious, or educational markets. Still, the economic market segment remains framed by the economic system's complexity-reducing function which, at the same time, underpins the systemic imperatives impelling the action of economic decision makers. Thus, the firm's reliance on the economic market governance of a specific set of transactions, i.e., the specific delineation of the firm-economic market boundary, indicates the firm's ability to adequately translate some of its dependencies on the outer environment into the complexity-reducing "language of prices" (Luhmann 1989, p. 62). Those dependencies that cannot be adequately translated into this language must remain internal to the firm. Distinct types of the theory of the firm deal with specific reasons why this translation cannot be successful. In also alluding to the legal market segment, the contract-based theories can be taken to argue that this translation would be thwarted by the problem of human opportunism which makes the devising and execution of contracts across firms prohibitively costly (Hodgson 1998, p. 180). In drawing on educational market metaphors, the competence-based theories, in contrast, take the primary translation obstacle to reside in "the largely non-communicable, idiosyncratic and non-contractible nature of competence" (Foss 1993, p. 139).Yet, whatever the specific nature of the translation problems may be, the firm may be seen as an enclave for phenomena which are essential for the fulfilment of systemic imperatives but are not adequately translatable into the language of prices. The list of such phenomena is potentially very long, and includes, among other things, truth, belief, loyalty, and power. All these phenomena must be fully embraced by the firm if it is to be competitive; but they are much too complex and subtle to be purchasable in the economic market setting.

The same processual point of view can be presented in a slightly different terminology. Oliver Williamson, a Nobel Prize-winning economist, took adaptation (a process!) to be "the central economic problem" (Williamson 1996, p. 101). He traced the same view in the work of Friedrich von Hayek (1945) and Chester Barnard (1938) who, however, referred to adaptation of very different kinds. Whereas Hayek (1945) held that the price system constitutes "an extraordinarily efficient" adaptation mechanism (Williamson 1996, p. 101), Barnard was primarily interested in the intra-organizational adaptation which is "conscious, 
deliberate, purposeful" (Barnard 1938, p. 4). Williamson (1996, p. 102) fully recognized that "both Hayek and Barnard are correct, because they are referring to adaptations of different kinds, both of which are needed in a high-performance system. The adaptations to which Hayek refers are those for which prices serve as sufficient statistics". The last sentence is remarkable in that it (almost) explicitly refers to the translatability of specific phenomena into the language of prices, with the implication that the limits of this translatability crystallize into the rationale of the firm. In terms of Hernes' (2008) interpretation of Whitehead, the firm accommodates those dimensions of concrete experience that cannot be converted into the abstract form of price as the expression of the economic system's complexity reduction.

The processual nature of the problem of the inadequate translatability into the language of prices is further confirmed by the fact that this translatability is suppressed by processual attributes such as change and turbulence. In a 1961 classic, Burns and Stalker drew the seminal distinction between the mechanistic and organic systems, the former of which relied on clear job descriptions which specified the limits of individual responsibility. While Burns and Stalker (ibid) associated the mechanistic systems with bureaucracy, the sheer clarity of job descriptions has a strong complexity-reducing aspect. Crucially, Burns and Stalker (ibid) see the changing business environment as a key driver for the rise of organic systems, in which "the boundaries of feasible demands on the individual disappear. The greatest stress is placed on his regarding himself as fully implicated in the discharge of any task appearing over his horizon, as involved not merely in the exercise of a special competence but in commitment to the success of the concern's undertakings approximating somewhat to that of the doctor or scientist in the discharge of his professional functions" (Burns and Stalker 1961/2001, p. xxii). In the recent literature, turbulence of the business environment is a widely acknowledged driver of the rise of stakeholder management as an alternative to "the mainstream view of shareholder capitalism" (Freeman et al. 2010, p. xv). Freeman et al. (2010, p. 35) explain that "as long as the environment is stable, few strategic surprises occur" and "the mainstream view of shareholder capitalism" may hold sway in the same way as the mechanistic structures in the context of Burns and Stalker (1961/2001). As the processual nature of the business environment makes itself manifest through the growing turbulence, the considerations of competitiveness necessitate a shift of managerial priorities from maximizing profits for shareholders to "creating as much value as possible for stakeholders, without resorting to trade-offs" (Freeman et al. 2010, p. 28).

\section{Concluding Remarks}

This paper has identified a productive tension between the systems-theoretic and processtheoretic philosophies and argued that this tension throws new light on the fundamental question about the nature of the firm. Luhmann was convinced that social systems, as he understood them, are more than mere analytical constructs; "the concept of system refers to something that is in reality a system and thereby incurs the responsibility of testing its statements against reality" (Luhmann 1995, p. 12). Process philosophers are no less adamant about the reality of processes, organisms, and internal relations. While there are good reasons to agree with both philosophies, their perfect complementarity is often said to be contravened by the fact that systems exhibit a number of features such as complexity reduction, operational closure, and indifference to the environment. These features do not seem 
to be well attuned to a processual worldview assuming each novel event to be "prehensively" influenced by the rest of the universe, but neither do they deny the latter's organic interconnectedness. The challenge to imagination posed by this tension helps to appreciate the philosophic meaning of the firm which turns out to be reposed on the paradoxical entanglement of the irreducibility of complexity reduction and the sustainability-requirements inherent to both personal and organizational forms of environmental observation.

Against this backdrop, the unique function of the firm is to house those aspects of this reality that are too unique, idiosyncratic, or organic to be accommodated by the "language of prices" corresponding, in institutional economics terms, to the reliance on market governance. The major examples of such aspects include technological complexity, organizational culture, competence, loyalty, commitment, and intrinsic motivation. The juxtaposition of the systems-theoretic and process-theoretic perspectives helps to diagnose and overcome the apparently predominant framing of the economic theory of the firm by the principle of complexity reduction as a key ingredient of the Luhmannian vision of the precariousness of system-environment relations. This framing per se is an adequate signifier of the complexity-reducing role of the economic function system, which, however, has often been referred to in ways that tend to side-line the critical dependence of this system on other function systems as well as its broader social and non-social environment. To do justice to this dependence, firms could act in their "organismic" quality; they could embrace, rather than disregard, the complexity of their environment. To the extent that they succeed in doing so, they develop dynamic capabilities (Nayak et al. 2019) and engage in "business ethics as practice" (Painter-Morland 2008), improving thereby their economic and social sustainability. Dynamic capabilities and business ethics are just two examples of the broad range of phenomena which have a strong bearing on firm survival but remain inchoate and mysterious to those theories of the firm that are wedded to simplistic over-identifications of systems theories with the complexity reduction principle. Qualifying this principle with new insights from process thinking opens up new avenues for scholarship on both the conceptual nature of the firm and its practical sustainability limits.

Acknowledgements The author is grateful to reviewers for their useful comments.

Funding Open Access funding enabled and organized by Projekt DEAL.

\section{Compliance with Ethical Standards}

Conflict of Interest There are no conflicts of interest. No data was used.

Open Access This article is licensed under a Creative Commons Attribution 4.0 International License, which permits use, sharing, adaptation, distribution and reproduction in any medium or format, as long as you give appropriate credit to the original author(s) and the source, provide a link to the Creative Commons licence, and indicate if changes were made. The images or other third party material in this article are included in the article's Creative Commons licence, unless indicated otherwise in a credit line to the material. If material is not included in the article's Creative Commons licence and your intended use is not permitted by statutory regulation or exceeds the permitted use, you will need to obtain permission directly from the copyright holder. To view a copy of this licence, visit http://creativecommons.org/licenses/by/4.0/.

\section{References}

Acquier A, Gond JP, Pasquero J (2011) Rediscovering Howard R. Bowen's legacy: the unachieved agenda and continuing relevance of social responsibilities of the businessman. Bus Soc 50(4):607-646 
Ahrne G, Brunsson N, Seidl D (2016) Resurrecting organization by going beyond organizations. Eur Manag J 34(2):93-101

Alchian AA, Demsetz H (1972) Production, information costs, and economic organization. Am Econ Rev 62(5):777-795

Barnard CI (1938) The functions of the executive. Harvard University Press, Cambridge

Barney J (1991) Firm resources and sustained competitive advantage. J Manag 17(1):99-120

Bowen HR (1953) Social responsibility of the businessman. Harper, New York

Burns T, Stalker GM (1961/2001) The management of innovation. Oxford University Press, New York

Chia R (2017) A process-philosophical understanding of organizational learning as "wayfinding”. Process, practices and sensitivity to environmental affordances. Learn Organ 24(2):107-118

Chia R, Holt R (2006) Strategy as practical coping: a Heideggerian perspective. Organ Stud 27(5):635-655

Christensen LT, Morsing M, Thyssen O (2013) CSR as aspirational talk. Organization 20(3):372-393

Coase RH (1937) The nature of the firm. Economica 4:386-405

Cobb JB (2007) Person-in-community: Whiteheadian insights into community and institution. Organ Stud 28(4):567-588

Cooren F, Seidl D (2019) Niklas Luhmann's radical communication approach and its implications for research on organizational communication. Acad Manag Rev. https://doi.org/10.5465/amr.2018.0176

Eisenhardt KM, Martin JA (2000) Dynamic capabilities: what are they? Strateg Manag J 21:1105-1121

Foss NJ (1993) Theories of the firm: contractual and competence perspectives. J Evol Econ 3(2):127-144

Freeman RE, Harrison JS, Wicks AC, Parmar B, de Colle S (2010) Stakeholder theory: the state of the art. Cambridge University Press, Cambridge

Grothe-Hammer M (2019) Organization without actorhood: Exploring a neglected phenomenon. EurManag J 37(3):325-338

Hernes T, Bakken T (eds) (2003) Autopoietic organization theory. Copenhagen Business School Press, Copenhagen

Hernes T (2008) Understanding organization as process: theory for a tangled world. Routledge, London

Hodgson GM (1998) Competence and contract in the theory of the firm. J Econ Behav Organ 35(2):179-201

Jackson MC (2019) Critical systems thinking and the management of complexity: responsible leadership for a complex world. Wiley, Oxford

Keahey J (2020) Sustainable development and participatory action research: a systematic review. SystPract Act Res. https://doi.org/10.1007/s11213-020-09535-8 (advance online publication)

Kroszner RS, Putterman L (2009) The economic nature of the firm. Cambridge University Press, Cambridge

Langley A, Tsoukas H (eds) (2017) The Sage Handbook of process organization studies. Sage, Thousand Oaks

Luhmann N (1982) The world society as a social system. Int J Gen Syst 8(3):131-138

Luhmann N (1989) Ecological communication. University of Chicago Press, Chicago

Luhmann N (1995) Social systems. Stanford University Press, Stanford

Mesle CR (2008) Process-relational philosophy. An introduction to Alfred North Whitehead. Templeton Foundation Press, Westconshohocken

Nayak A, Chia R (2011) Thinking becoming and emergence: process philosophy and organization studies. Res Sociol Organ 32:281-309

Nayak A, Chia R, Canales JI (2019) Non-cognitive microfoundations: understanding dynamic capabilities as idiosyncratically refined sensitivities and predispositions. AcadManag Rev. https://doi. org/10.5465/amr.2016.0253

Painter-Morland M (2008) Business ethics as practice: ethics as the everyday business of business. Cambridge University Press, Cambridge

Pies I, Schreck P, Homann K (2019) Single-objective versus multi-objective theories of the firm: using a constitutional perspective to resolve an old debate. Rev ManagSci. https://doi.org/10.1007/s1184 6-019-00376-x

Plaza-Úbeda JA, Pérez-Valls M, Céspedes-Lorente JJ, Payán-Sánchez B (2020) The contribution of systems theory to sustainability in degrowth contexts: the role of subsystems. Syst Res BehavSci 37(1):68-81

Ramírez MC, Castaño LAN, Delgado Á, González MA, Caicedo LC, Peralta M (2019) Promoting entrepreneurship through a community learning model-case study: green businesses. SystPract Act Res 32(6):629-643

Roth S (2018) Market therapy? On intervention in the consociation with non-members. Syst Res BehavSci 35(1):127-138 
Roth S, Valentinov V (2020) East of nature. Accounting for the environments of social sciences. Ecol Econ 176:106734

Roth S, Schwede P, Valentinov V, Pérez-Valls M, Kaivo-oja J (2020) Harnessing big data for a multifunctional theory of the firm. EurManag J 38(1):54-61

Teece DJ (2007) Explicating dynamic capabilities: the nature and microfoundations of (sustainable) enterprise performance. Strateg Manag J 28(13):1319-1350

Teece DJ (2012) Dynamic capabilities: routines versus entrepreneurial action. J Manage Stud 49(8):1395-1401

Thompson S, Valentinov V (2017) The neglect of society in the theory of the firm: a systems-theory perspective. Camb J Econ 41(4):1061-1085

Tortia EC (2018) The firm as a common. Non-divided ownership, patrimonial stability and longevity of co-operative enterprises. Sustainability 10(4):1023

Valentinov V (2014) The complexity-sustainability trade-off in NiklasLuhmann's social systems theory. Systems Research and Behavioral Science 31(1):14-22

Valentinov V (2020) Corporate social responsibility and the nonprofit sector: exploring the common ground. Kybernetes, advance online publication. https://doi.org/10.1108/K-06-2020-0397

Valentinov V, Perez Valls M (2021) A conception of moral wayfinding for business managers: the obligation for a sustainable corporation. J Clean Prod, article No. 284

Valentinov V, Thompson S (2019) The supply and demand of social systems: towards a systems theory of the firm. Kybernetes 48(3):570-585

von Bertalanffy L (1968) General system theory: foundations, development, applications. George Braziller, New York

von Hayek FA (1945) The use of knowledge in society. Am Econ Rev 35(4):519-530

Wabule A (2020) Beyond rules of procedures: Utilising participatory action research (PAR) to enhance reflective practice and normative professionalism. SystPract Act Res 33:393-408

Whitehead AN (1929) Science and the modern world. Cambridge University Press, Cambridge

Whitehead AN (1978) Process and reality: an essay in cosmology. The Free Press, New York

Williamson OE (1996) The mechanisms of governance. Oxford University Press, Oxford

Wolf WB (1974) The basic Barnard: an introduction to Chester I. Barnard and his theories of organization and management. Humphrey Press, Ithaca

Zenger TR, Felin T, Bigelow L (2011) Theories of the firm-market boundary. AcadManag Ann 5(1):89-133 